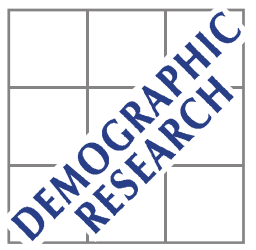

Demographic Research a free, expedited, online journal of peer-reviewed research and commentary in the population sciences published by the Max Planck Institute for Demographic Research Konrad-Zuse Str. 1, D-18057 Rostock · GERMANY www.demographic-research.org

DEMOGRAPHIC RESEARCH

VOLUME 21, ARTICLE 31 PAGES 915-944

PUBLISHED 17 DECEMBER 2009

http://www.demographic-research.org/Volumes/Vol21/31/

DOI: 10.4054/DemRes.2009.21.31

Research Article

\title{
High suburban fertility: Evidence from four Northern European countries
}

\section{Hill Kulu}

Paul J. Boyle

Gunnar Andersson

(C) 2009 Hill Kulu, Paul J. Boyle \& Gunnar Andersson.

This open-access work is published under the terms of the Creative Commons Attribution NonCommercial License 2.0 Germany, which permits use, reproduction \& distribution in any medium for non-commercial purposes, provided the original author(s) and source are given credit. See http:// creativecommons.org/licenses/by-nc/2.0/de/ 


\section{Table of Contents}

1 Introduction $\quad 916$

$2 \quad$ Previous research on suburban fertility 918

$3 \quad$ Hypotheses 920

3.1 Data, methods and definitions 921

3.2 Fertility across residential contexts in four Northern European 924

4 Discussion $\quad 935$

$5 \quad$ Acknowledgements 938

$\begin{array}{ll}\text { References } & 939\end{array}$ 


\title{
High suburban fertility: Evidence from four Northern European countries
}

\author{
Hill Kulu' \\ Paul J. Boyle ${ }^{2}$ \\ Gunnar Andersson ${ }^{3}$
}

\begin{abstract}
While numerous studies have compared urban and rural fertility rates across Europe, virtually no studies have distinguished suburbs as a distinct residential context. This study examines fertility variation across different residential contexts in four Northern European countries: Denmark, Finland, Norway and Sweden. We move beyond the conventional urban-rural focus of most previous studies of within-nation variations in fertility by distinguishing between urban centres and suburbs of cities and towns. We base our study on aggregate and individual-level register data and our analysis shows that fertility levels are significantly higher in suburbs than in urban centres; this pattern has persisted over the past quarter of a century for all four countries. A parity-specific analysis of Swedish register data reveals that total fertility varies between central cities and suburbs due to the relatively high first- and second-birth propensities in the suburbs. Further analysis shows that fertility variation between the central cities and suburbs persists after controlling for women's socio-economic characteristics. We discuss the role of various factors in accounting for high suburban fertility including omitted individual characteristics, contextual factors and selective residential moves of couples planning to have a child, suggesting that more study is required of this underresearched topic.
\end{abstract}

\footnotetext{
${ }^{1}$ Department of Geography, School of Environmental Sciences, University of Liverpool, Roxby Building, Liverpool, L69 7ZT, United Kingdom.

${ }^{2}$ Longitudinal Studies Centre - Scotland (LSCS), School of Geography and Geosciences, University of St Andrews, St Andrews, Scotland KY16 9AL, United Kingdom.

${ }^{3}$ Department of Sociology, Stockholm University, 10691 Stockholm, Sweden.
} 


\section{Introduction}

There is a large and growing literature which charts national-level variation in fertility across Europe, with many studies contrasting the low fertility in countries of Southern and Eastern Europe with the higher fertility in countries of the North and West (Kohler, Billari and Ortega 2002; Andersson and Neyer 2004; Frejka et al. 2008; Thornton and Philipov 2009). These national-level analyses of fertility variation within Europe remain an asset in the development of a greater understanding of low and lowest-low fertility; for example, an intriguing 'convergence debate' has arisen which asks whether national fertility variation is narrowing (Wilson 2001) or not (Frejka and Calot 2001; Coleman 2002). However, while numerous theories have been posited for these national differences, Caldwell and Schindlmayr (2003) argue that simplistic models that focus mainly on welfare systems or family structures are too restrictive. They emphasize the complex array of contextual variables which may contribute to historical and geographical differences in fertility.

Given this background, it is surprising that so little contemporary European research has focused on fertility variation within nations. A number of historical studies demonstrate the considerable within-nation variation in fertility that existed around the time of the first 'demographic transition'. Sharlin (1986) showed that urban fertility (both marital and overall) was lower than rural fertility prior to the demographic transition, and during the transition it decreased earlier and more rapidly. Watkins (1990) went on to argue for the importance of local context and peer networks in explaining individual fertility behaviour (see also Anderson 1986). Focusing on nineteenth-century England, Garrett et al. (2001) demonstrated that fertility decline was not prompted by a single cause, as individuals with similar characteristics had very different fertility levels depending on where they lived. Szreter (1996) emphasized the importance of community-level values and attitudes, suggesting that the environmental context influenced how community groups altered their reproductive regimes (Szreter and Garrett 2000). Combined, these historical studies make a persuasive case for the recognition of the socio-spatial context in understanding fertility behaviour.

More recently, Boyle (2003) argues that within-nation variations in fertility behaviour may provide useful clues to our understanding of contemporary low fertility. A few recent European studies have indeed considered such variation, finding that rural fertility levels continue to be higher than those in urban areas, regardless of whether they are observed in medium, low or lowest-low fertility countries. This holds for France (Fagnani 1991), Italy (Michielin 2004), Estonia (Kulu 2005), West Germany (Hank 2001), the Netherlands (Mulder and Wagner 2001), Austria and Poland (Kulu 2006), Denmark, Finland, Norway and Sweden (Kulu et al. 2007), and Britain (Boyle et al. 2008). 
While these studies make an important contribution to our understanding of within-nation fertility patterns, we argue that distinguishing only between urban and rural areas is too narrow. Choosing an appropriate scale for within-nation fertility analyses is difficult but, if possible, it is essential to distinguish between areas which experience significantly different patterns. A major geographical dimension which has been neglected in these recent studies is city suburbs. A number of early studies from the US drew attention to the relatively high fertility rates in the suburbs of urban areas (Goldstein and Mayer 1965; Kiser et al. 1968) and some recent US studies also emphasise the need to separate metropolitan central-city and suburban environments when exploring family formation (Heaton et al. 1989; Snyder et al. 2004; Snyder 2006; Brown and Snyder 2006), although these studies do not focus on fertility in particular. However, we find virtually no scientific studies which consider suburban fertility in contemporary Europe. Given the large number of people that reside in suburbs within Europe, many of whom may have made residential decisions that were influenced by the suitability of these areas for bringing up children, this seems amiss. As the contextual characteristics of suburbs and central cities often differ between Europe and the US, there is a need for in-depth studies that focus also on the behaviour in European settings. And, if fertility rates are indeed higher in city suburbs than in city centres, the combination of these areas in previous studies may have led to an under-estimation of the extent of low fertility in central cities.

In this study, we compare fertility levels by urban, suburban and rural areas in four Northern European countries - Denmark, Finland, Norway and Sweden. First, we examine fertility variation across residential contexts from the mid-1970s to the early twenty-first century. Such a temporal analysis allows us to determine how persistent any observed differences may have been. Second, we study the extent to which the population composition accounts for fertility variation across residential contexts and the extent to which other factors, possibly contextual ones, play a role. An important reason for considering four Nordic countries is that data from the population registers of these countries allow us to study the variation in fertility across residential contexts in great detail and for an extended period of time.

This is a follow-up paper to Kulu et al. (2007). We exploit the same data-set and follow the similar logic of data analysis. However, the focus of this paper is different. While in that previous study we examined fertility levels by settlement size (urbanrural), we now focus on fertility differences between urban centres and suburbs. We regard the lack of focus on suburban areas as a major omission in the local geography of fertility. The fact that our results demonstrate how significantly different fertility rates are in urban (lower) and suburban (higher) areas means that previous studies which combined urban and suburban areas together may have been biased. 


\section{Previous research on suburban fertility}

The research on suburban fertility dates back to the 1950s and 1960s when industrialised countries experienced both the post-war baby boom and increasing suburbanisation. Using the 1950 US census data several studies found an inverse relationship between fertility levels and size of place of residence. Furthermore, the research showed that within urban areas fertility was consistently higher in the suburbs than in the central cities (Duncan and Reiss 1956; Kiser 1959). A study by Freedman et al. (1959), however, showed only minor differences in expected family size between central city and suburban residents in the US. This surprising finding was attributed to the fact that the Catholic population, which had more children than the Protestants, was concentrated in the city centres. The study initiated a series of further studies that examined fertility differences between Catholics and Protestants in the US and how fertility patterns of different religious groups interacted with their residence (e.g. Zimmer and Goldscheider 1966; Weller and Bouvier 1972).

Interestingly, a closer look at the results provided by Freedman et al. (1959: 312) reveals that their study supports the findings of previous research and that the controversy was partly irrelevant. Suburban women, both Catholics and Protestants, had a significantly higher completed family size at the moment of interview than women living in central cities; the largest families were observed in rural areas, as expected. The authors discussed the various advantages of suburban context for family living emphasising that suburbs are less densely populated, that more families can afford to live in detached houses or larger apartments, that there is more room for children to play, and that more adequate schools are available than in city centres. Therefore, it seemed reasonable to expect suburban couples to have somewhat larger families than couples living in large cities. However, Freedman et al. (1959: 311-312) maintained that it remained an open question whether couples move to suburbs because they want more children (a selective mobility effect), or whether living in the suburbs leads couples to want more children (a suburban contextual effect).

The 1960 US census gave rise to another set of studies on suburban fertility. Using census data and vital statistics by census tract Goldstein and Mayer (1965) examined the cumulative and current fertility of women living in different residential contexts in Rhode Island, showing that women in suburban areas had higher fertility than those living in central-city areas. However, higher suburban fertility was restricted to the high-status suburbs. Kiser et al. (1968) extended the analysis of spatial fertility variation to the whole of US. Their study showed that fertility varied inversely with the size of the place of residence and that rural women who lived closer to a large city were less fertile than those who lived in more distant rural areas. However, fertility levels on the fringes of the cities (suburbs) were still higher than in central cities. 
There was little (if any) research on suburban fertility in the international literature during the 1970s and 1980s. This is despite the fact that the process of suburbanization itself attracted considerable attention in these decades. Since the late 1980s, however, another related stream of research has emerged, focusing on residential differences in family formation in the US, and distinguishing within metropolitan areas between the residents of central cities and those of suburbs. Heaton et al. (1989) examined differences in the timing of three family life-course transitions in young adulthood: first intercourse, first birth and first marriage. Using longitudinal survey data their analysis showed that young people in rural areas marry earlier than those living in urban areas, particularly in the city centres. Further analysis revealed that part but not all of the urban-rural difference was attributed to compositional effects. The authors concluded that young people growing up in rural areas were exposed to an environment that encourages early marriage. The pattern of early marriage suggested that sexual activity and childbearing were more closely linked to marriage in rural than in urban areas (Heaton et al. 1989: 13). The study also showed that young people living in American suburbs delay parenthood longer than central-city residents. This pattern persisted after controlling for compositional factors.

A subsequent study on residential differences in marriage formation by McLaughlin et al. (1993) supported the idea that rural women marry earlier than urban women, and research by Snyder et al. (2004) revealed that in the US rural women were more likely to marry directly without prior cohabitation. In the American context, suburban women, in turn, seem to exhibit union-formation patterns which are in between those of rural and central-city women. More recently, Snyder (2006) analysed non-marital fertility of American women born 1951-1980 and showed that rural residence was associated with more traditional family patterns, including a higher proportion of first conception within marriage and a preference for marriage following a non-marital conception. Interestingly, patterns for suburban women were very similar to those of the rural women - both displayed equally traditional family-formation patterns and behaviours.

Brown and Snyder (2006) reach similar conclusions in their recent study on residential differences in union transitions of cohabiting women in the US. They show that rural and suburban cohabiting women have similar propensities to marry or separate, whereas central-city women have relatively low propensities to marry their cohabiting partners. Cohabiting unions of rural and suburban women are shorter on average. They transform more rapidly to either formalisation through marriage or termination through separation, suggesting that rural and suburban couples are more likely to cohabit on their path to marriage.

To summarise, there are two US research streams looking at family or fertility patterns of suburban populations. In the 1950s and 1960s, a set of studies examined 
fertility variation in the US by residential contexts. These studies showed that suburban residents had higher fertility than those living in central cities. More recent research focuses on residential differences in patterns in family formation in the US and shows that young people in suburbs display distinct family-formation patterns, which are closer to the patterns of rural populations than those of central-city residents. The early research was mainly descriptive and provided little analysis of the role of compositional and contextual factors in accounting for high suburban fertility. Recent research has addressed contextual factors in more detail showing that population composition explains part of the variation in family formation across residential contexts, but that contextual effects still persist. There is, however, little discussion on what these contextual factors actually might be. Further, the main focus of recent studies (in the US) has been on partnership formation; childbearing patterns have received surprisingly little attention.

This study contributes to the literature in a number of ways. First, we examine fertility differences between central cities and suburbs in four Northern European countries over an extended period of time, allowing us to detect long-term developments in patterns of this kind. Second, we investigate fertility timing across residential contexts and time. Third, we study parity-specific fertility to gain a better understanding of the underlying reasons for any aggregate fertility differentials between central cities and suburbs. Fourth, we examine whether, and the extent to which, the socio-economic characteristics of populations account for fertility variation across residential contexts. This is the first study of its type, based on reliable registration data for four countries over a long time period. The results indeed demonstrate that fertility rates are consistently and persistently different in suburban areas, suggesting that subsequent studies should shy away from simple comparisons of urban / rural fertility trends.

\section{Hypotheses}

Our hypotheses are based on previous research, and are as follows. First, we expect fertility levels to vary significantly by residential context, being higher in suburbs of cities (and in rural areas) than in central cities (Freedman et al. 1959; Kiser et al. 1968; Snyder 2006). High fertility in suburbs relative to that in central cities may be related to compositional factors (e.g., fewer students live in suburbs), selective residential moves of couples intending to have a child, and contextual effects which may relate to people's attitudes to childbearing and raising children. While some suggest that fertility differences by residential context have decreased over time (Coleman 1996), we still expect to observe significant fertility differences between central cities and suburbs 
because of the factors discussed above (cf. Hank 2001; Kulu 2005; 2006). Second, we expect to observe differences in fertility timing such that women in suburbs have children earlier than women in central cities (Kulu et al. 2007; cf. McLaughlin et al. 1993; Snyder 2004). Again, this is related to the fewer students in suburban areas (who tend to delay childbirth), and to the fact that young people who plan to have a child more early may leave cities for suburbs, and that the family-friendly environment in suburbs may promote an earlier onset of childbearing.

Third, parity-specific fertility rates are expected to vary between suburbs and central cities. Previous studies suggest that differences by residential context in the likelihood of having the first child may be more important than differences in higherorder parity transitions (Kulu et al. 2007). Fourth, we expect that socio-economic differences, particularly the over-representation of students in central cities, should explain some fertility variation between suburbs and cities, at least for first birth behaviour (Hank 2001). Finally, we do not expect substantial differences in results between the four Nordic countries, as they to a large extent share a similar history and institutional context.

\subsection{Data, methods and definitions}

Our data come from the population registers of the four Nordic countries. For each, we have access to the annual number of births by age of mother across municipalities (by single-year age groups for Denmark, Norway and Sweden and by five-year age groups for Finland) and the female resident populations by age at the beginning of each year over the period 1975-2003 (1976 and onwards for Finland $)^{4}$. The data enable us to calculate the annual total fertility and mean age at childbearing for various residential contexts in each country over about a quarter of a century. In addition, we have access to anonymised individual childbearing histories from Swedish population registers for all women born in Sweden in 1945 and later. These data allow us to also calculate parity-specific occurrence-exposure fertility rates across residential contexts - with and without controlling for a number of socio-economic variables.

In the latter analysis, we first computed parity-specific fertility rates for Swedishborn women, by residential contexts standardized for age of woman and time since any previous birth. Thereafter, we also standardized these fertility rates for a set of socioeconomic characteristics (educational enrolment, educational level attained and earnings in a given year) to reveal the extent to which spatial variations in fertility can be explained by the characteristics of women in these areas. For educational attainment

\footnotetext{
${ }^{4}$ In the Nordic countries, a municipality usually consists of a city or town with its nearest hinterland or of some economically and culturally linked smaller rural settlements.
} 
we distinguish between primary, secondary and tertiary levels. For earnings we divide women into those with low earnings (first to third deciles of the relative earnings distribution of women and the few women without own earnings); medium earnings (fourth to seventh deciles); and high earnings (eighth to tenth deciles). When calculating standardized parity-specific fertility rates, we use the event history method developed and implemented by Jan Hoem $(1987 ; 1993)$.

First, we distinguished six types of residential contexts according to the size of the municipality of residence (as measured in 1999-2001): 1) cities with a population larger than 400,000, which includes the four capital cities of Copenhagen, Helsinki, Oslo and Stockholm and the city of Gothenburg in Sweden; 2) other cities with populations of more than 100,000 ; 3) larger towns with $50,000-100,000$ inhabitants; 4) towns with 10,000-50,000 inhabitants; 5) small towns with 5,000-10,000 inhabitants; and 6) rural municipalities, with fewer than 5,000 inhabitants. In a second step, we singled out suburban municipalities that neighboured cities and towns with more than 50,000 people (categories 1-3 above). When defining suburban areas we used commuting data from 1998-2000 and assigned a municipality to an urban region if at least $20 \%$ of its employed population commuted there. Using commuting data to define 'travel-to-work' or labour-market regions is standard in migration and urbanisation research, although the threshold used varies across studies (see Champion 2001; Hugo et al. 2003). We chose the 20-per-cent threshold as this has been used by several studies on internal migration in the Nordic countries (Kupiszewski et al. 2001a; 2001b). ${ }^{5}$

Table 1 shows the distribution of women aged 15-49 across residential contexts in the four countries. The data from 2003 show that about 20 to $25 \%$ of women in reproductive ages live in suburban municipalities of cities and towns, with the biggest group being the residents in the suburbs of the capital cities (10 to $15 \%$ of all women). The size of the female population in the suburbs has been relatively stable over the last quarter of a century, although the share of women living in the suburbs of the capital city has increased in Finland, while it has decreased slightly in Denmark.

\footnotetext{
${ }^{5}$ The statistical offices of each of the four countries provided us with data on: 1) the number of employed people living in municipality $a$ in year $t$; and 2) the number who worked in the neighbouring / nearest city or town in that year. We asked for information on commuters only for cities and towns with populations larger than 50,000. For smaller settlements, the labour-market area rarely extends beyond the borders of the municipality. The commuting data were only available for 1998, 1999 or 2000. In some cases, labour-market areas of cities and towns may have extended over time, meaning that some areas which were classified as suburbs for the whole observation period, based on the statistics from 1998-2000, might not have been suburbs in the late 1970s and the 1980s. Given that these areas were mostly rural areas at that time, and that fertility in rural areas has been persistently high, we may thus have overestimated suburban fertility in the late 1970 s and the 1980s. However, we have indirect evidence that the bias is minor, if not negligible. Comparison of the results with different criteria for labour markets in 1998-2000 (10, 20 or 30-per-cent thresholds) shows no substantial differences.
} 
Table 1: Female population at reproductive ages (15-49) by residential contexts in four Nordic countries, 1975, 1985, 1995 and 2003 (per cent)

\begin{tabular}{|c|c|c|c|c|}
\hline & 1975 & 1985 & 1995 & 2003 \\
\hline \multicolumn{5}{|l|}{ Denmark } \\
\hline Copenhagen & 12 & 11 & 12 & 14 \\
\hline Suburbs of Copenhagen & 17 & 16 & 15 & 14 \\
\hline Cities, centre & 12 & 12 & 13 & 13 \\
\hline Cities, suburbs & 5 & 5 & 5 & 5 \\
\hline Towns, centre & 10 & 10 & 10 & 10 \\
\hline Towns, suburbs & 3 & 3 & 3 & 3 \\
\hline Medium-sized towns & 29 & 29 & 29 & 28 \\
\hline Small towns & 11 & 12 & 12 & 11 \\
\hline Rural areas & 1 & 1 & 1 & 1 \\
\hline Total & 100 & 100 & 100 & 100 \\
\hline \multicolumn{5}{|l|}{ Finland } \\
\hline Helsinki & 12 & 11 & 12 & 13 \\
\hline Suburbs of Helsinki & 9 & 11 & 12 & 13 \\
\hline Cities, centre & 10 & 9 & 10 & 11 \\
\hline Cities, suburbs & 5 & 5 & 6 & 6 \\
\hline Towns, centre & 12 & 12 & 11 & 12 \\
\hline Towns, suburbs & 4 & 5 & 5 & 5 \\
\hline Medium-sized towns & 25 & 25 & 24 & 23 \\
\hline Small towns & 13 & 13 & 12 & 11 \\
\hline Rural areas & 10 & 9 & 9 & 8 \\
\hline Total & 100 & 100 & 100 & 100 \\
\hline \multicolumn{5}{|l|}{ Norway } \\
\hline Oslo & 13 & 12 & 12 & 13 \\
\hline Suburbs of Oslo & 11 & 12 & 11 & 11 \\
\hline Cities, centre & 13 & 12 & 11 & 12 \\
\hline Cities, suburbs & 4 & 5 & 5 & 5 \\
\hline Towns, centre & 5 & 4 & 6 & 6 \\
\hline Towns, suburbs & 2 & 2 & 2 & 2 \\
\hline Medium-sized towns & 26 & 27 & 30 & 29 \\
\hline Small towns & 12 & 13 & 12 & 11 \\
\hline Rural areas & 14 & 14 & 12 & 11 \\
\hline Total & 100 & 100 & 100 & 100 \\
\hline \multicolumn{5}{|l|}{ Sweden } \\
\hline Stockholm and Gothenburg & 13 & 13 & 14 & 16 \\
\hline Suburbs of $S$ and $G$ & 13 & 14 & 14 & 14 \\
\hline Cities, centre & 14 & 14 & 15 & 16 \\
\hline Cities, suburbs & 4 & 4 & 4 & 4 \\
\hline Towns, centre & 18 & 17 & 17 & 17 \\
\hline Towns, suburbs & 2 & 2 & 2 & 2 \\
\hline Medium-sized towns & 31 & 31 & 29 & 27 \\
\hline Small towns & 4 & 4 & 3 & 3 \\
\hline Rural areas & 1 & 1 & 0 & 0 \\
\hline Total & 100 & 100 & 100 & 100 \\
\hline
\end{tabular}

Source: Population registers of Denmark, Finland, Norway and Sweden. 


\subsection{Fertility across residential contexts in four Northern European countries}

Figures $1 \mathrm{a}$ to $1 \mathrm{~d}$ present the total fertility across residential contexts for the four Nordic countries from the mid-1970s up to 2003. There was significant variation in fertility across settlements in all four countries. In general, the larger the municipality, the lower the fertility. Further, the lowest fertility levels were observed in residents of capital cities, followed by those living in other central cities and towns. Fertility levels in suburbs were significantly higher than in central municipalities and similar to the levels in small towns and rural areas.

Figure 1a: Total fertility by residential context in Denmark, 1975-2003
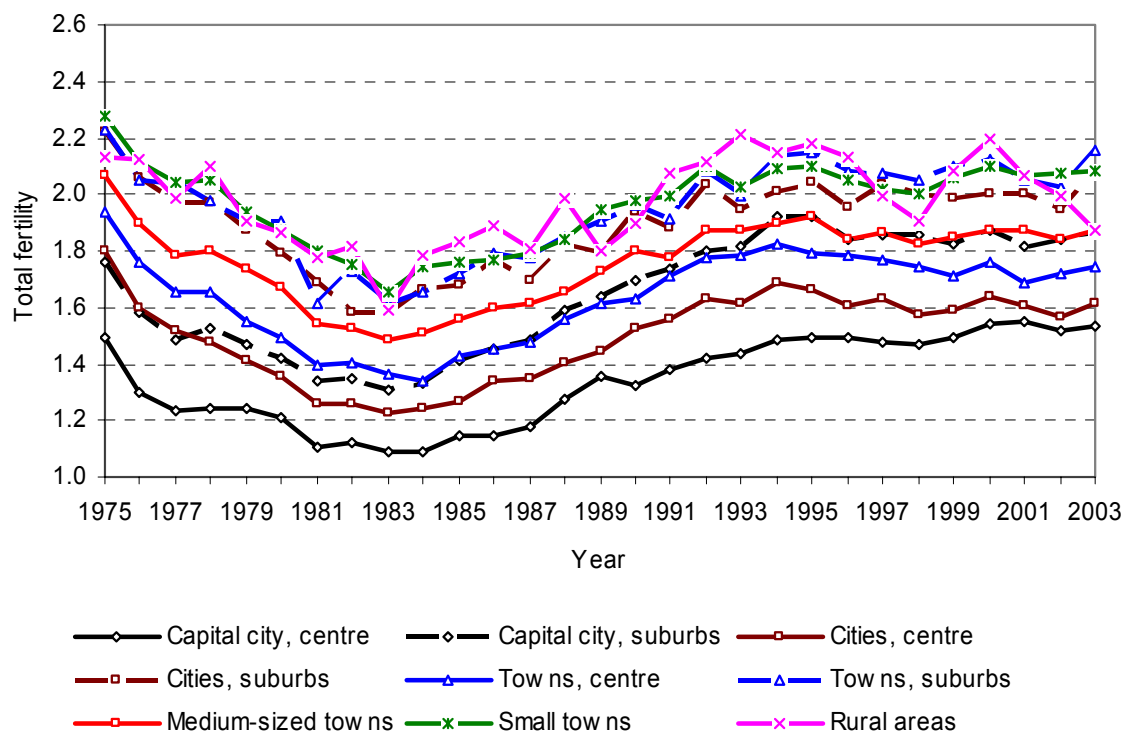
Figure 1b: Total fertility by residential context in Finland, 1976-2003
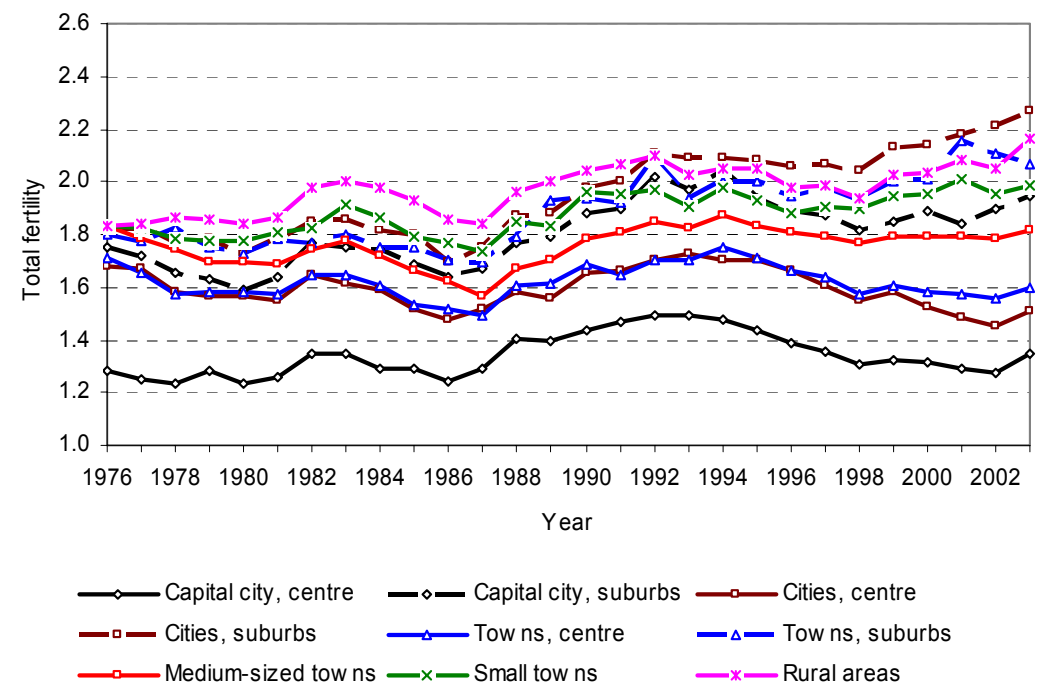

Figure 1c: Total fertility by residential context in Norway, 1975-2003
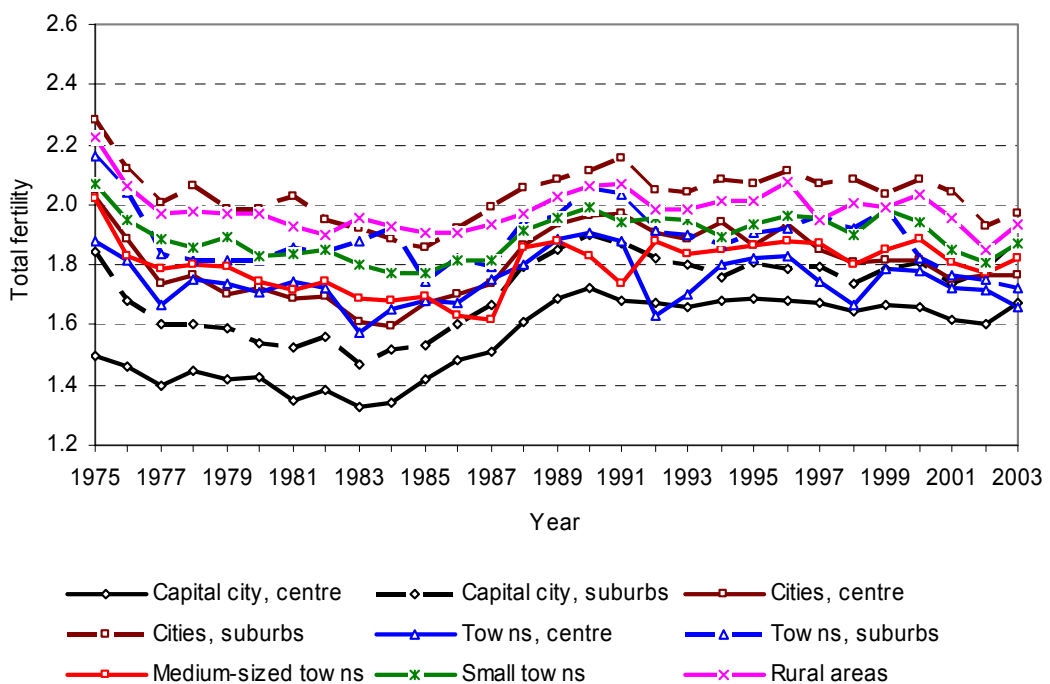
Figure 1d: Total fertility by residential context in Sweden, 1975-2003

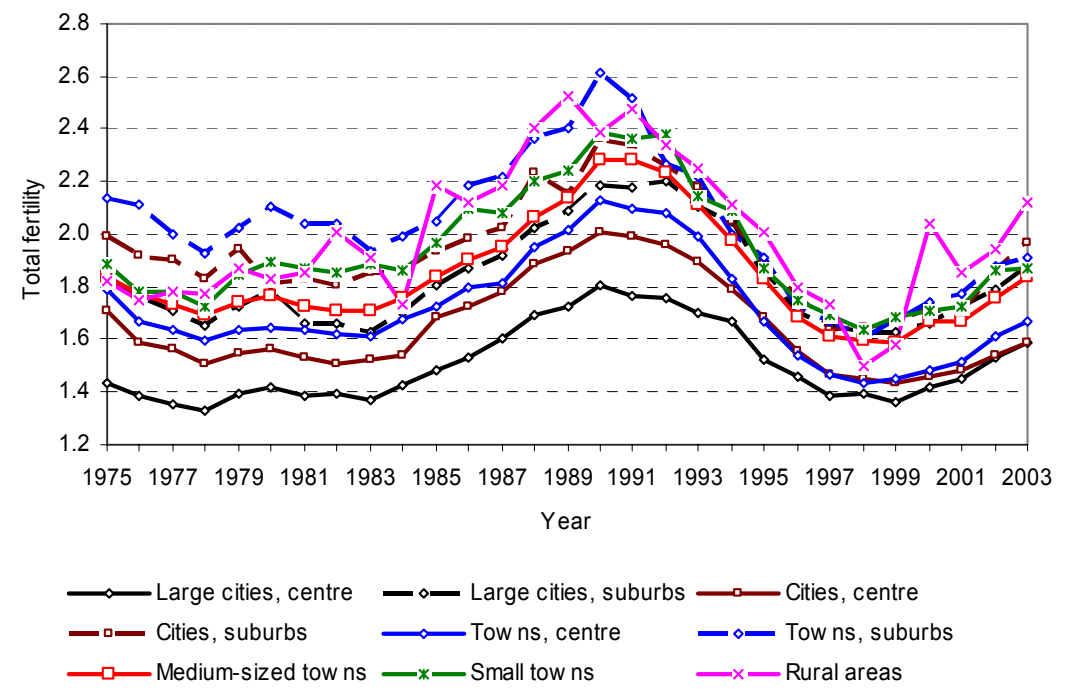

Source: Population registers of Denmark, Finland, Norway and Sweden.

Figures $2 \mathrm{a}$ to $2 \mathrm{~d}$ provide further information on the relative fertility differentials between central cities/towns and their suburbs. We see that in all four countries, throughout the last quarter of a century, fertility was significantly higher in suburban municipalities than in central cities and towns. Interestingly, the differences remained stable over time in the three Scandinavian countries, but increased in Finland in the 1990s. Perhaps to some extent this is related to a change in 1996 in the Finnish registration system, which shifted the recorded place of residence of students from their parental home to their place of study (mostly in student accommodations in larger cities). The most recent figures show that the fertility of women in suburbs in Denmark, Sweden and Norway was higher than in the central municipalities by some 10 to $25 \%$, whereas in Finland this difference was as large as 40 to 50\%. 
Figure 2a: Total fertility in suburbs relative to total fertility in urban centres in Denmark, 1975-2003

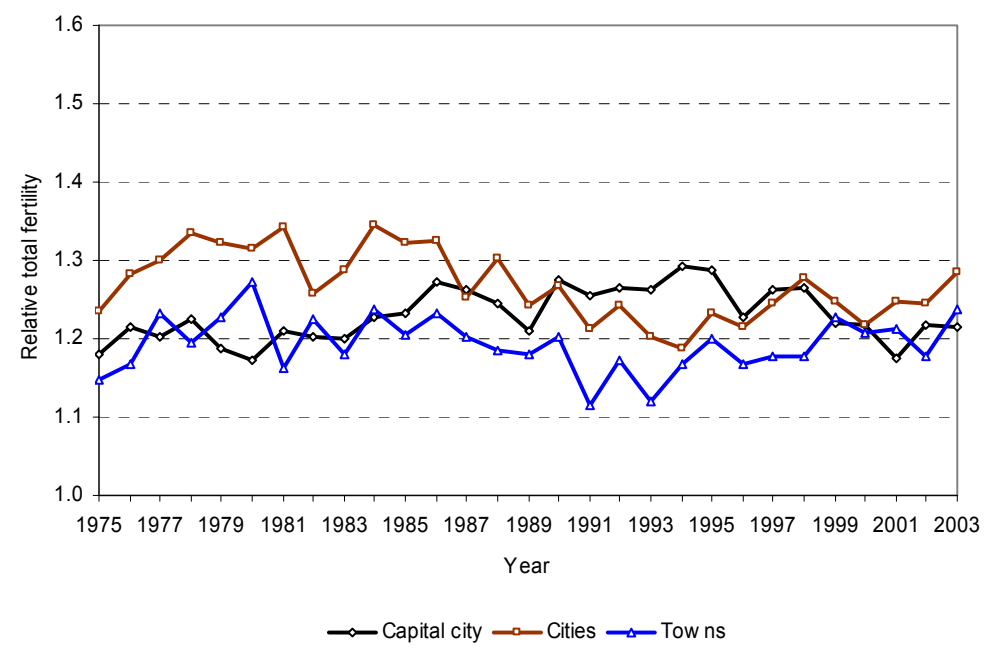

Figure 2b: Total fertility in suburbs relative to total fertility in urban centres in Finland, 1976-2003

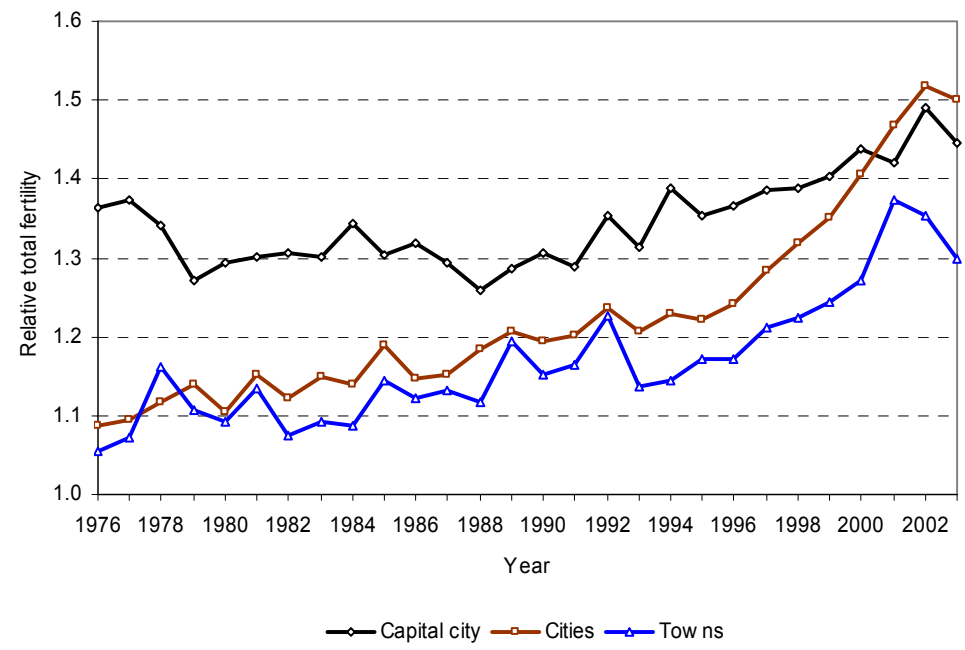


Figure 2c: Total fertility in suburbs relative to total fertility in urban centres in Norway, 1975-2003

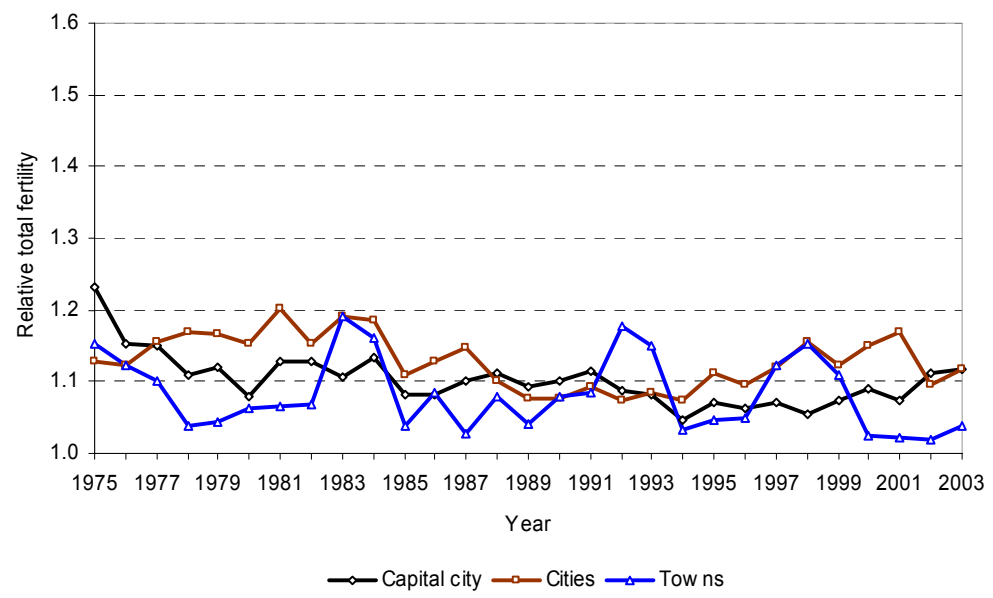

Figure 2d: Total fertility in suburbs relative to total fertility in urban centres in Sweden, 1975-2003

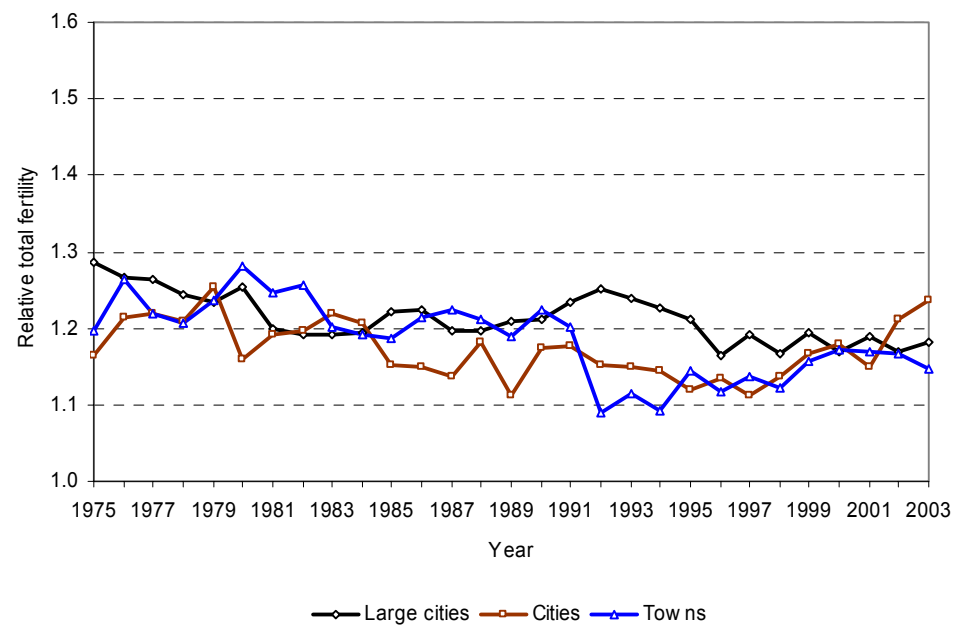

Source: Population registers of Denmark, Finland, Norway and Sweden. 
Figures $3 \mathrm{a}$ to $3 \mathrm{~h}$ present the mean age at childbearing for women in the various residential contexts at the beginning and end of our study period. These figures provide insight into changes in the timing of fertility. We calculated the mean age at childbearing for various residential contexts in the four countries for two three-year periods: one for the mid-1970s (1975-77) and another for the early twenty-first century (2001-03). We see that in the mid-1970s the timing of childbearing was rather similar across residential contexts - the mean age at childbearing did not vary much by women's residence. The results for 2001-03 reveal that significant fertility postponement had taken place in all residential contexts, and that the phenomenon was most pronounced in larger places. For all countries, there were also systematic differences in fertility timing between central cities and suburbs, with the mean age at childbearing being significantly higher in the cities than the suburbs.

Figure 3a: Mean age at childbearing by residential context in Denmark, 1975-77

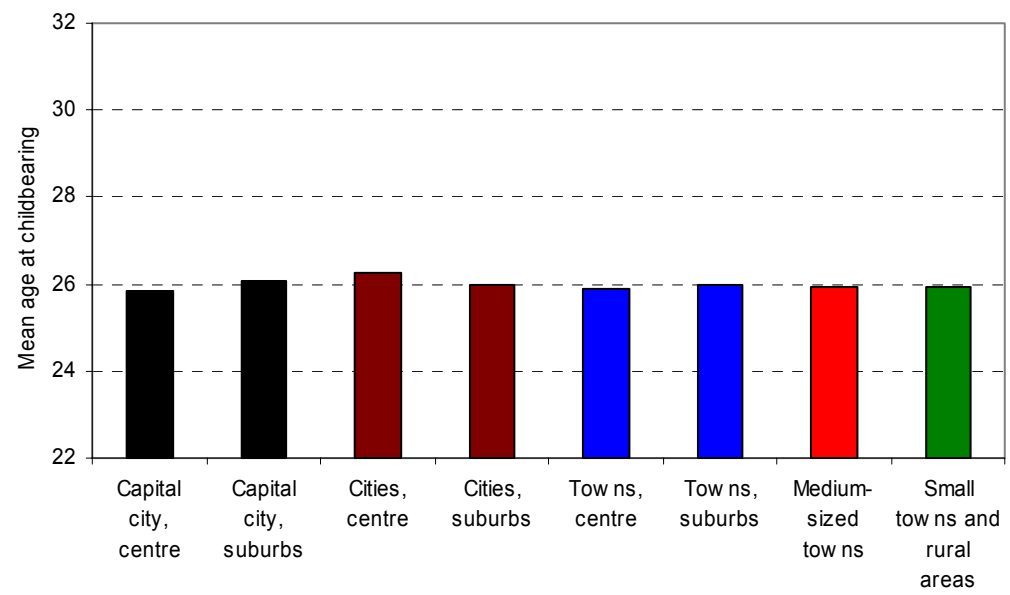

Place of residence 
Figure 3b: Mean age at childbearing by residential context in Denmark, 2001-03

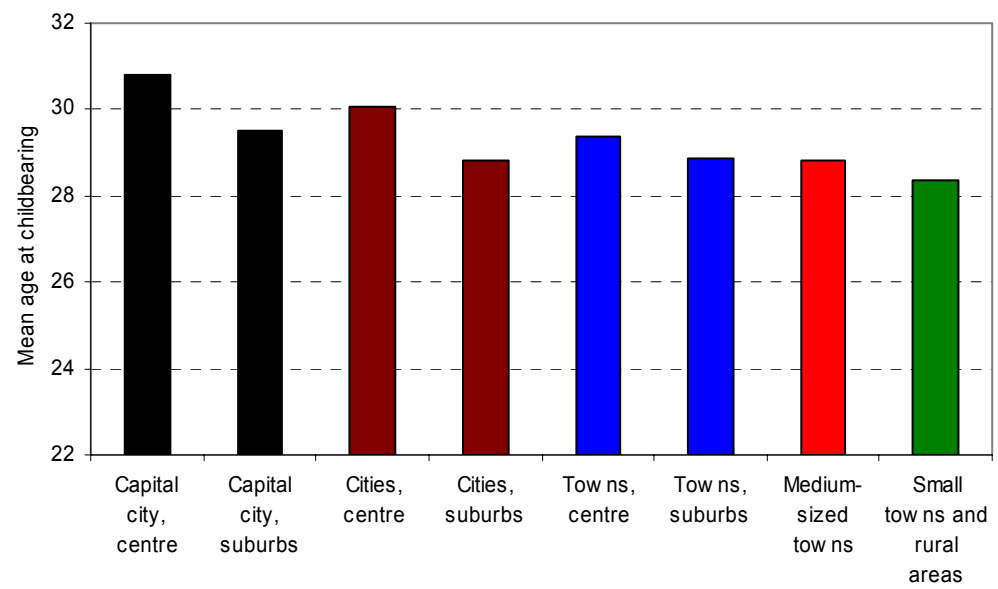

Place of residence

Figure 3c: Mean age at childbearing by residential context in Finland, 1976-78

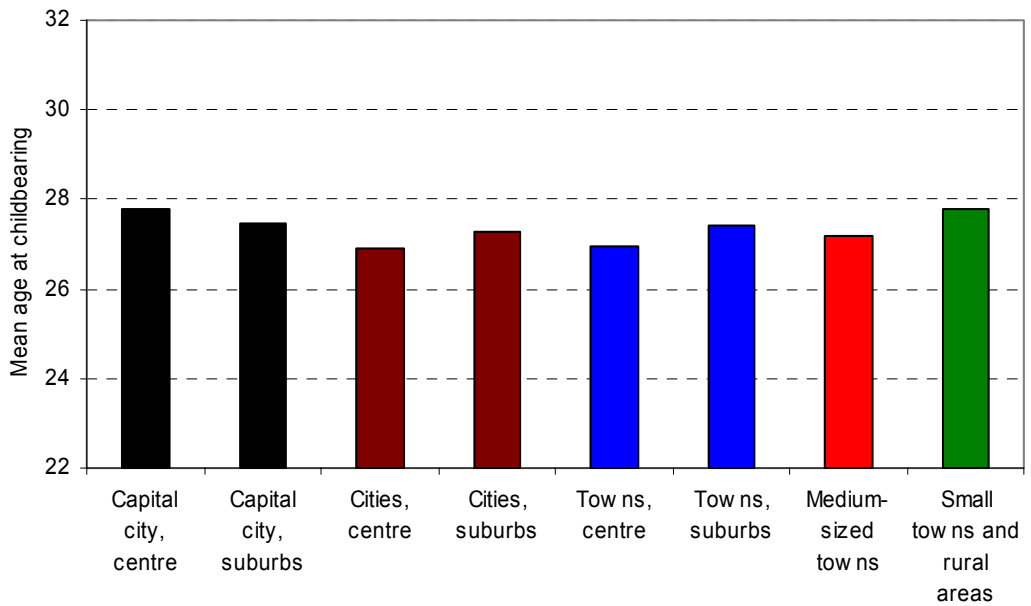

Place of residence 
Figure 3d: Mean age at childbearing by residential context in Finland, 2001-03

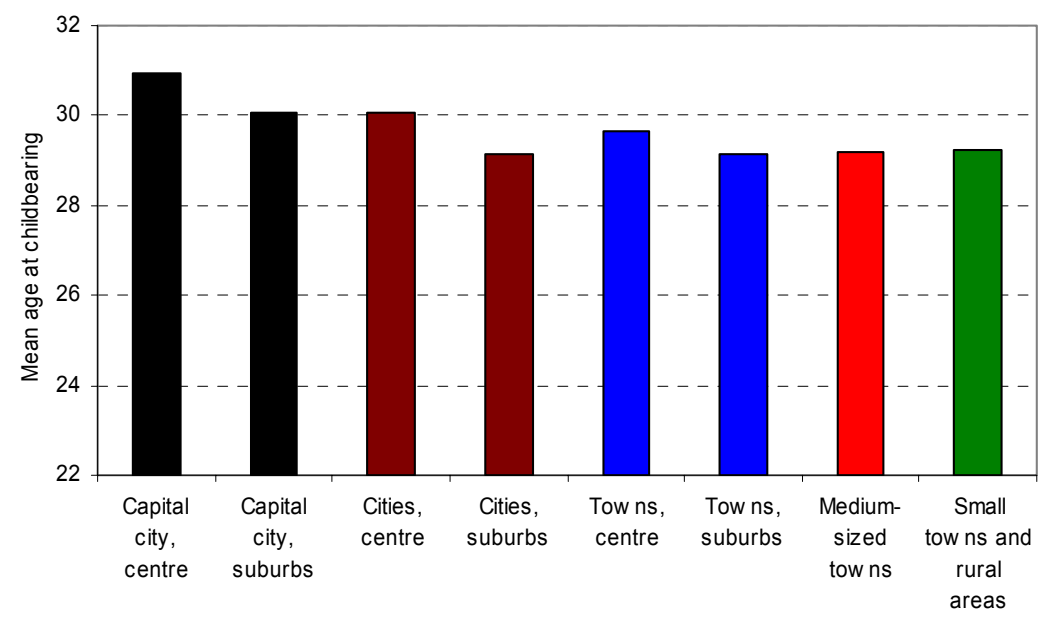

Place of residence

Figure 3e: Mean age at childbearing by residential context in Norway, 1975-77

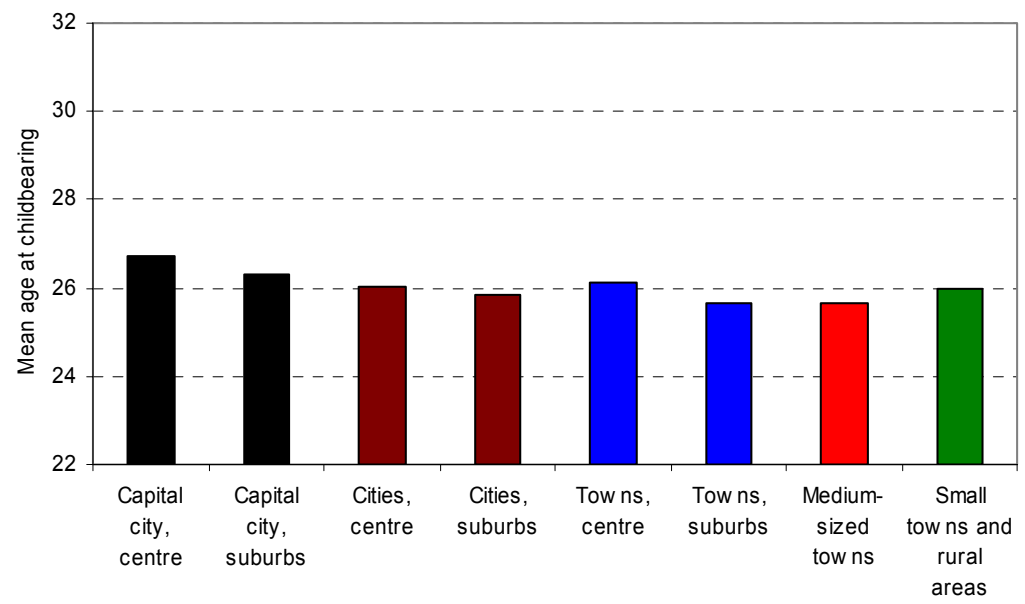

Place of residence 
Figure 3f: Mean age at childbearing by residential context in Norway, 2001-03

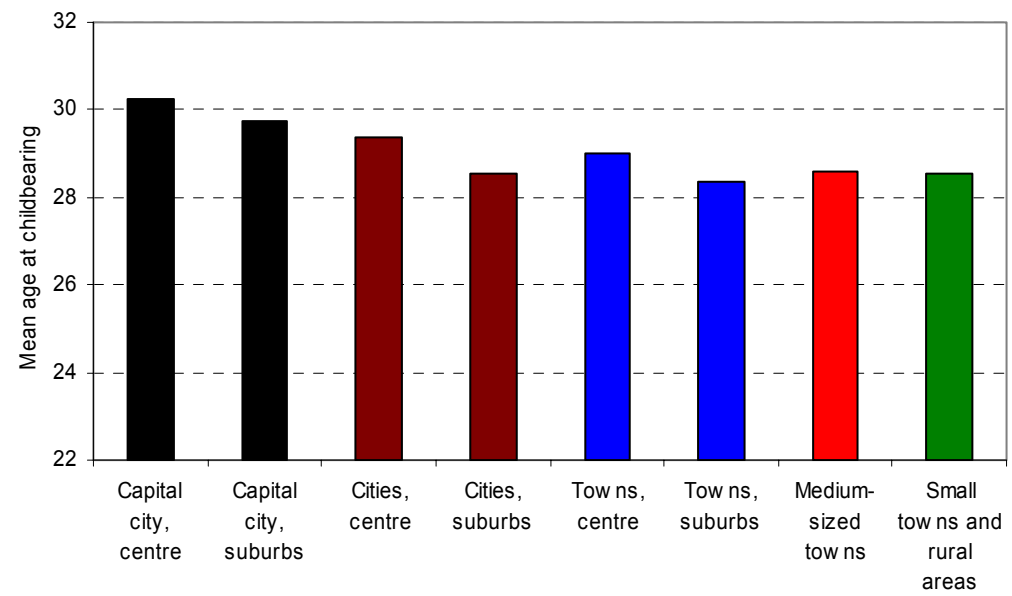

Place of residence

Figure 3g: Mean age at childbearing by residential context in Sweden, 1975-77

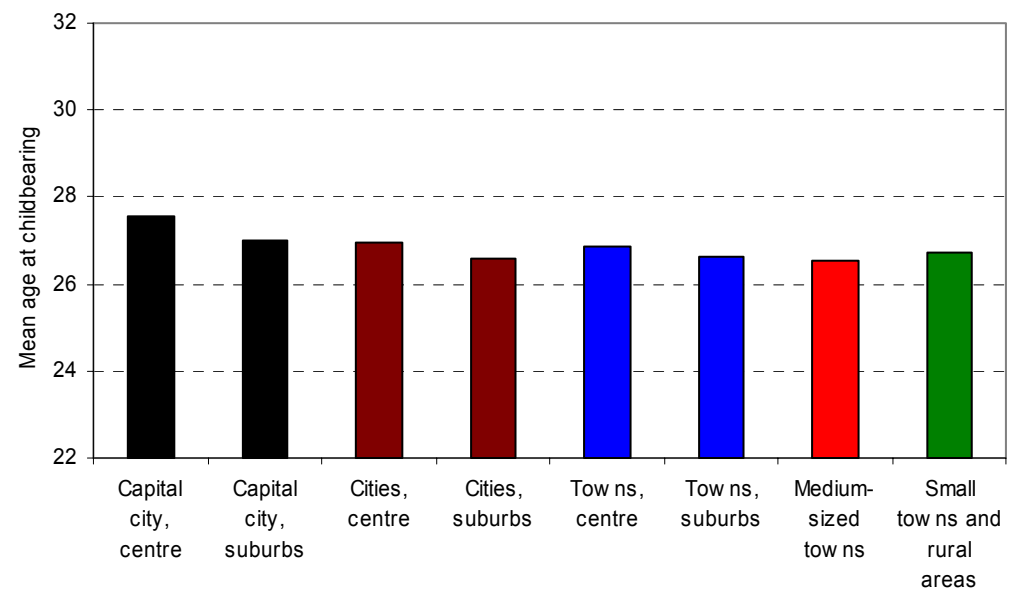

Place of residence 
Figure 3h: Mean age at childbearing by residential context in Sweden, 2001-03

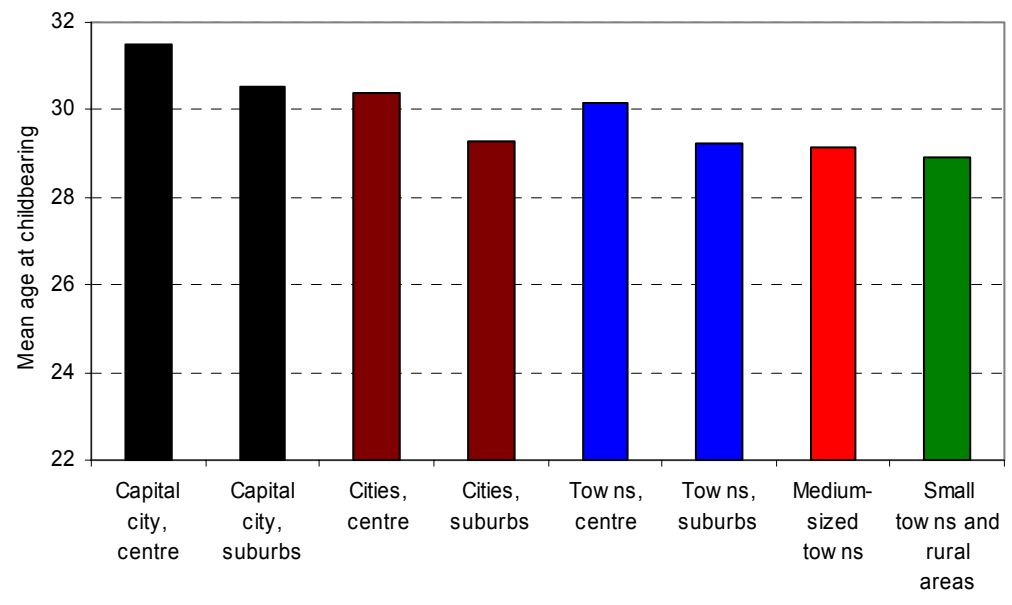

Place of residence

Source: Population registers of Denmark, Finland, Norway and Sweden.

Next, we extend our analysis by investigating the parity-specific childbearing behaviour across residential contexts, using data from Sweden for 1981-99. Table 2 presents relative parity-specific fertility rates by municipality group, distinguishing between central cities and suburbs for urban areas with more than 50,000 people. Firstbirth rates are presented for childless women aged 15-29 and 30-45, separately. All rates are given relative to the rates in the centres of the two largest urban areas (the cities of Stockholm and Gothenburg). Model 1 presents rates standardized for age of woman and time since any previous birth. We see that first-birth rates for younger women are inversely related to municipality size, while for older women the relationship is slightly positive. In both cases, however, first-birth rates are significantly higher in suburbs than in the central cities. For younger women, suburban residents exhibit $30-40 \%$ higher first-birth rates than women living in central cities; for older women the difference is $10-20 \%$.

For second and third births the fertility levels are highest for women in rural areas and small towns and smallest for women in large cities, as expected. However, while women in suburban municipalities have 10-20\% higher second-birth rates than women living in central cities, there was no such difference in third-birth behaviour. 
Kulu, Boyle \& Andersson: High suburban fertility

Table 2: Relative rates of first, second and third births, by residential context in Sweden, 1981-99

\begin{tabular}{|c|c|c|c|c|}
\hline & $\begin{array}{l}\text { Model 1: } \\
\text { rates relative } \\
\text { to large city } \\
\text { centres }^{1}\end{array}$ & $\begin{array}{l}\text { Model 1: } \\
\text { rates relative to the } \\
\text { associated city or } \\
\text { town centre }{ }^{1}\end{array}$ & $\begin{array}{l}\text { Model 2: } \\
\text { rates relative } \\
\text { to large city } \\
\text { centres }^{2}\end{array}$ & $\begin{array}{l}\text { Model 2: } \\
\text { rates relative to the } \\
\text { associated city or } \\
\text { town centre }^{2}\end{array}$ \\
\hline \multicolumn{5}{|l|}{ First births at ages 15-29 } \\
\hline Stockholm and Gothenburg & 1 & 1 & 1 & 1 \\
\hline Suburbs of $S$ and $G$ & 1.41 & 1.41 & 1.35 & 1.35 \\
\hline Cities, centre & 1.32 & 1 & 1.35 & 1 \\
\hline Cities, suburbs & 1.86 & 1.41 & 1.82 & 1.35 \\
\hline Towns, centre & 1.47 & 1 & 1.48 & 1 \\
\hline Towns, suburbs & 1.95 & 1.33 & 1.89 & 1.28 \\
\hline Medium-sized towns & 1.82 & & 1.77 & \\
\hline Small towns and rural areas & 1.99 & & 1.95 & \\
\hline \multicolumn{5}{|l|}{ First births at ages $30-44$} \\
\hline Stockholm and Gothenburg & 1 & 1 & 1 & 1 \\
\hline Suburbs of $S$ and $G$ & 1.19 & 1.19 & 1.24 & 1.24 \\
\hline Cities, centre & 0.94 & 1 & 0.99 & 1 \\
\hline Cities, suburbs & 1.04 & 1.11 & 1.20 & 1.21 \\
\hline Towns, centre & 0.96 & 1 & 1.04 & 1 \\
\hline Towns, suburbs & 1.05 & 1.09 & 1.20 & 1.15 \\
\hline Medium-sized towns & 0.93 & & 1.08 & \\
\hline Small towns and rural areas & 0.90 & & 1.09 & \\
\hline \multicolumn{5}{|l|}{ Second births } \\
\hline Stockholm and Gothenburg & 1 & 1 & 1 & 1 \\
\hline Suburbs of $S$ and $G$ & 1.19 & 1.19 & 1.20 & 1.20 \\
\hline Cities, centre & 1.10 & 1 & 1.10 & 1 \\
\hline Cities, suburbs & 1.21 & 1.10 & 1.23 & 1.12 \\
\hline Towns, centre & 1.11 & 1 & 1.12 & 1 \\
\hline Towns, suburbs & 1.22 & 1.10 & 1.24 & 1.11 \\
\hline Medium-sized towns & 1.18 & & 1.21 & \\
\hline Small towns and rural areas & 1.26 & & 1.29 & \\
\hline \multicolumn{5}{|l|}{ Third births } \\
\hline Stockholm and Gothenburg & 1 & 1 & 1 & 1 \\
\hline Suburbs of $S$ and $G$ & 1.02 & 1.02 & 1.03 & 1.03 \\
\hline Cities, centre & 1.02 & 1 & 1.03 & 1 \\
\hline Cities, suburbs & 1.01 & 0.99 & 1.04 & 1.01 \\
\hline Towns, centre & 1.04 & 1 & 1.06 & 1 \\
\hline Towns, suburbs & 1.04 & 1.00 & 1.07 & 1.01 \\
\hline Medium-sized towns & 1.09 & & 1.12 & \\
\hline Small towns and rural areas & 1.23 & & 1.28 & \\
\hline
\end{tabular}

${ }^{1}$ Model 1: Birth rates are standardized for age of woman and time since any previous birth.

${ }^{2}$ Model 2: First-birth rates are additionally standardized for educational enrolment and attainment, and for earnings; second-birth and third-birth rates are standardised for educational attainment (earnings were excluded from the final models as their effect was not important).

Source: Population registers of Denmark, Finland, Norway and Sweden. 
Finally, we study the extent to which socio-economic characteristics account for fertility variation across residential contexts using parity-specific fertility rates that are standardized for woman's educational enrolment, educational attainment and earnings in a given year (Model 2, Table 2). Controlling for socio-economic characteristics does not change the geographical patterns much: younger women in suburban areas still exhibit 30-35\% higher first-birth rates than those in central cities, and for older women the difference is $15-25 \%$. Second-birth rates in suburbs are $10-20 \%$ higher than in central cities. To summarise, women in Swedish suburban municipalities have higher first- and second-birth rates than women living in central cities, whereas there are no differences in the third-birth rates of those who have already had two children; furthermore, the socio-economic characteristics of women account for only a negligible part of the geographical fertility differentials we observe.

\section{Discussion}

We examined childbearing patterns across residential contexts in four Northern European countries. We moved beyond the usual urban-rural focus of previous studies by distinguishing between urban centres and suburbs of cities and towns and showed that this is an important geographical distinction to make. First, fertility levels are significantly higher among women in suburbs than among those living in urban centres; this pattern persisted over a quarter of a century for all four countries. Second, we observed differences in fertility timing across contexts for the most recent period - the mean age at childbearing was higher in the central cities than in suburbs (although the differences were not that large). Third, our parity-specific analysis of Swedish register data revealed that much of the variation in total fertility between central cities and suburbs in this country was attributed to relatively high first- and also second-birth propensities in the suburbs. Fourth, fertility variation between the central cities and suburbs persisted after controlling for women's socio-economic characteristics. Finally, as expected, patterns in the four countries were relatively similar.

These results lead to the question of what explains high fertility in suburban contexts relative to central cities in the four Northern European countries? First, it is possible that some further compositional characteristics of populations might explain the differences. Partnership status was not included in the analysis of parity-specific fertility but being in union or married is clearly related to childbearing. It is likely that an over-representation of cohabiting or married women in the suburbs is associated with the high first-birth rates observed there (cf. Brown and Snyder 2006; Snyder 2006). However, the direction of causality between partnership and childbearing is not as selfevident as it may appear at first glance. People often decide to form a union or marry 
because they wish to have children and the decision to start childbearing could be seen as a reason for union formation. Therefore, there are likely to be other factors, possibly contextual ones, which influence both the decision to form a union and have a child (cf. Snyder 2006).

Second, while women's education and income were included in our models, we did not control for their partner's characteristics, which might also contribute to fertility variation. However, previous studies for the Nordic countries have shown that in the context of a relatively high educational homogamy and the prevalence of dual-earner couples, woman's educational and labour market characteristics are good proxies for the household's labour market performance and income and its association with fertility (cf. Andersson et al. 2005; Andersson and Scott 2007). Thus, we expect that the inclusion of data on the partner's education and employment would be unlikely to make a significant difference to the patterns we observe. Moreover, the women's education and earnings explained little, if any, of the fertility variation between central cities and their suburbs.

Third, international migration may have an impact on our results. Immigrants often tend to reside in larger cities, but in the Nordic countries they are, to a varying degree, over-represented both in central cities and some of the suburbs to these cities (Andersson 1998; Blom 1999). Typically, they have elevated fertility shortly after migration (Andersson 2004; Milewski 2007). Still, the relative effect of immigrant behaviour on total fertility levels of the four Nordic countries remains small. ${ }^{6}$

Fourth, it is likely that selective residential moves explain a significant part of the high fertility in city suburbs. Recent studies demonstrate that many couples change their residence when waiting for a child to be born, perhaps because of a need to adjust housing size to accommodate the increasing family size or because of the perceived suitability of the suburban environment for childrearing (Mulder and Wagner 2001; Kulu 2008). In many such cases, the child is conceived when the couple still lives in the city or shortly after the move to the suburb. High suburban fertility would thus be the outcome of selective moves rather than a suburban residential effect. However, the effect of selective residential moves on suburban fertility may not be as large as we think. Our recent study using longitudinal data from Finland shows that couples who moved from urban centres to surrounding suburbs indeed had elevated fertility levels after moving, thus supporting the idea of selective residential moves (Kulu and Boyle 2009). Interestingly, however, fertility levels in the suburbs were not much influenced by selective moves as the 'migrant' couples only formed a small share of the total suburban population in the Finnish context; more people had grown up in the suburbs

\footnotetext{
${ }^{6}$ In order to remove the impact of international migration on results, our parity-specific analysis of fertility in Sweden was based on Swedish-born women only
} 
or had moved there before they formed a union. Most importantly - the fertility among these longer-term residents was also high.

Finally, high suburban fertility could be associated with the fact that many suburban couples live in relatively large apartments or in detached or semi-detached houses (cf. Kulu and Vikat 2007). On the one hand, housing can be seen as a proxy for some household-specific unobserved characteristics that may influence childbearing behaviour, such as household economic resources or financial support from parents. On the other hand, housing can be regarded as a contextual variable in itself, reflecting the living conditions and immediate environment of a family. Apartments in Nordic suburbs are normally larger than in central cities, and detached or semi-detached houses are common. The layout of the latter differs from that of apartments and often includes a garden, which is often considered important by families with small children. Further, the housing type cannot easily be separated from the character of the surrounding environment as suburban living in Finland, Norway or Sweden most often involves living in the vicinity of nature. Thus, both housing conditions and the broader suburban environment may simultaneously account for high levels of suburban fertility. Indeed, the lure of the suburbs for many parents or prospective parents is likely to be related to the family-friendly environment they are considered to offer. Suburban residents are also more likely to be surrounded by other families with children both because of the higher fertility in these areas and the residential moves of families with small children from urban centres to the suburbs. As a result, local cultural values, which we may regard a reflection of a 'modern rurality', are likely to support the relatively high suburban fertility.

Clearly, now that we have demonstrated the amount of variation between city and suburban fertility, and that suburban fertility patterns may actually be closer to the patterns in rural areas than in the city and town centres, further research is needed to investigate the causes of high suburban fertility. First, the childbearing patterns of native or long-term urban, rural and suburban residents should be examined and compared with the fertility of those who have moved at various stages of their family and childbearing careers. The question is whether couples who move from central cities to suburbs with an intention of having a child are also more likely to have an additional child later on, compared to if they had remained in the city. If movers to suburbs have higher fertility than stayers in central cities it raises the question of whether this is indeed a sign of their adaptation to the suburban context, or rather indicates selectivity, based on their long-term family plans. Second, it might be interesting to consider the flows in the opposite direction as younger adults moving out of suburbs into city centres may also be selective, or may be influenced to some extent by the context they have entered. Third, fertility variation within suburbs should be examined with an aim 
to find out what is specific to suburbs with high fertility and those with lower fertility, provided that the variation does exist.

To conclude, it is tempting to see the 'invisible hand' of selective moves behind high suburban fertility. However, it is also likely that other factors may contribute to the high fertility in suburbs. Thus, we accept that selective mobility (or immobility) have a role to play, but believe that larger and better housing, lower density and more easygoing social interaction in family-friendly areas are also important factors that promote childbearing in the suburbs (cf. Kohler 2000; Lutz and Qiang 2002; Kulu and Vikat 2007). These are issues, which need to be examined in future studies.

\section{Acknowledgements}

We are grateful to the statistical central bureaus of the four Nordic countries for providing us with the raw data used in this study. We also thank Max Planck Institute for Demographic Research for supporting Hill Kulu's research stay at the institute. We appreciate the valuable comments on a previous version of this paper provided by two referees and the editor of Demographic Research. Further, we have much benefitted from discussions with Clara Mulder, Hans-Peter Kohler, Tom Cooke, Franz-Josef Kemper and Gunnar Malmberg. 


\section{References}

Anderson, B. (1986). Regional and cultural factors in the decline of marital fertility in Western Europe. In: Coale, A. and Watkins, S. (eds.). The Decline of Fertility in Europe. Princeton: Princeton University Press: 293-313.

Andersson, G. (2004). Childbearing after migration: Fertility patterns of foreign-born women in Sweden. International Migration Review 38(2): 747-774. doi:10.1111/j.1747-7379.2004.tb00216.x.

Andersson, G., Duvander, A.-Z., and Hank, K. (2005). Erwerbsstatus und Familienentwicklung in Schweden aus paarbezogener Perspektive. In: Tölke, A. and Hank, K. (eds.). Männer - Das ,vernachlässigte' Geschlecht in der Familienforschung [Sonderheft 4 der Zeitschrift für Familienforschung]. Wiesbaden: VS Verlag für Sozialwissenschaften: 220-234.

Andersson, G. and Neyer, G. (2004). Contemporary research on European fertility. Demographic Research SC3(1): 1-14. doi:10.4054/DemRes.2004.S3.1.

Andersson, G. and Scott, K. (2007). Childbearing dynamics of couples in a universalistic welfare state: The role of labor-market status, country of origin, and gender. Demographic Research 17(30): 897-938. doi:10.4054/DemRes.2007.17.30.

Andersson, R. (1998). Socio-spatial dynamics: Ethnic divisions of mobility and housing in post-Palme Sweden. Urban Studies 35(3): 397-428. doi:10.1080/0042098984835.

Blom, S. (1999). Residential concentration among immigrants in Oslo. International Migration 37(3): 617-641. doi:10.1111/1468-2435.00086.

Boyle, P.J. (2003). Population geography: Does geography matter in fertility research? Progress in Human Geography 27(5): 615-626. doi:10.1191/0309132503ph452pr.

Boyle, P.J., Graham, E., and Feng, Z. (2008). Contextualising demography: The significance of local clusters of fertility in Scotland. Rostock: Max Planck Institute for Demographic Research (MPIDR working paper, WP-2008-036).

Brown, S.L. and Snyder, A.R. (2006). Residential differences in cohabitors' union transitions. Rural Sociology 71(2): 311-334. doi:10.1526/003601106777789729. 
Caldwell, J. and Schindlmayr, T. (2003). Explanations of the fertility crisis in modern societies: A search for commonalities. Population Studies 57(3): 241-263. doi:10.1080/0032472032000137790.

Champion, A.G. (2001). Urbanization, sub-urbanization, counterurbanization, and reurbanization. In: Paddison, R. (ed.). Handbook of Urban Studies. London: Sage: $143-161$.

Coleman, D. (1996). New patterns and trends in European fertility: International and sub-national comparisons. In: Coleman, D. (ed.). Europe's Population in the 1990s. Oxford: Oxford University Press: 1-61.

Coleman, D. (2002). Populations of the industrial world - a convergent demographic community?. International Journal of Population Geography 8(5): 319-344. doi:10.1002/ijpg.261.

Duncan, O.D. and Reiss, A.J. (1956). Social Characteristics of Urban and Rural Communities, 1950. New York: John Wiley \& Sons.

Fagnani, J. (1991). Fertility in France: The influence of urbanization. In: Bähr, J. and Gans, P. (eds.). The Geographical Approach to Fertility. Kieler Geographische Schriften 78. Kiel: Geographisches Institut der Universität Kiel: 165-173.

Freedman, R., Whelpton, P.K., and Campbell, A.A. (1959). Family Planning, Sterility and Population Growth. New York: McGraw-Hill.

Frejka, T. and Calot, G. (2001). Cohort reproductive patterns in low-fertility countries. Population and Development Review 27(1): 103-132. doi:10.1111/j.17284457.2001.00103.x.

Frejka, T., Sobotka, T., Hoem, J.M., and Toulemon, L. (eds.) (2008). Childbearing trends and policies in Europe. Demographic Research S7.

Garrett, E., Reid, A., Schürer, K., and Szreter, S. (2001). Changing Family Size in England and Wales: Place, Class and Demography, 1891-1911. Cambridge: Cambridge University Press.

Goldstein, S. and Mayer, K.B. (1965). Residence and status differences in fertility. The Milbank Memorial Fund Quarterly 43(3): 291-310. doi:10.2307/3348815.

Hank, K. (2001). Regional fertility differences in western Germany: An overview of the literature and recent descriptive findings. International Journal of Population Geography 7(4): 243-257. doi:10.1002/ijpg.228. 
Heaton, T.B., Lichter, D., and Amoateng, A. (1989). The timing of family formation: Rural-urban differentials in first intercourse, childbirth, and marriage. Rural Sociology 54(1): 1-16.

Hoem, J.M. (1987). Statistical analysis of a multiplicative model and its application to the standardization of vital rates: A review. International Statistical Review 55(2): 119-152. doi:10.2307/1403190.

Hoem, J.M. (1993). Classical demographic models of analysis and modern eventhistory techniques. In: IUSSP, 22nd International Population Conference, Montreal, Canada Volume 3. Montreal: International Union for the Scientific Study of Population: 281-291.

Hugo, G., Champion, A., and Lattes, A. (2003). Toward a new conceptualization of settlements for demography. Population and Development Review 29(2): 277297. doi:10.1111/j.1728-4457.2003.00277.x.

Kiser, C.V. (1959). Fertility rates by residence and migration. In: International Population Conference, Vienna 1959. Vienna: International Union for the Scientific Study of Population: 273-286.

Kiser, C.V., Grabill, W.H., and Campbell, A.A. (1968). Trends and Variations in Fertility in the United States. Cambridge: Harvard University Press.

Kohler, H.-P. (2000). Social interaction and fluctuations in birth rates. Population Studies 54(2): 223-232. doi:10.1080/713779084.

Kohler, H.-P., Billari, F.C., and Ortega, J.A. (2002). The emergence of lowest-low fertility in Europe during the 1990s. Population and Development Review 28(4): 641-680. doi:10.1111/j.1728-4457.2002.00641.x.

Kulu, H. (2005). Migration and fertility: Competing hypotheses re-examined. European Journal of Population 21(1): 51-87. doi:10.1007/s10680-005-3581-8.

Kulu, H. (2006). Fertility of internal migrants: Comparison between Austria and Poland. Population, Space and Place 12(3): 147-170. doi:10.1002/psp.406.

Kulu, H. (2008). Fertility and spatial mobility in the life-course: Evidence from Austria. Environment and Planning A 40(3): 632-652. doi:10.1068/a3914.

Kulu, H. and Boyle, P.J. (2009). High fertility in city suburbs: Compositional or contextual effects?. European Journal of Population 25(2): 157-174. doi:10.1007/s10680-008-9163-9. 
Kulu, H. and Vikat, A. (2007). Fertility differences by housing type: The effect of housing conditions or of selective moves?. Demographic Research 17(26): 775802. doi:10.4054/DemRes.2007.17.26.

Kulu, H., Vikat, A., and Andersson, G. (2007). Settlement size and fertility in the Nordic countries. Population Studies 61(3): 265-285. doi:10.1080/00324720701571749.

Kupiszewski, M., Illeris, S., Durham, H., and Rees, P. (2001a). Internal migration and regional population dynamics in Europe: Denmark case study. Leeds: The University of Leeds, School of Geography (Working Paper 01/02).

Kupiszewski, M., Borgegård, L.-E., Fransson, U., Håkansson, J., Durham, H., and Rees, P. (2001b). Internal migration and regional population dynamics in Europe: Sweden case study. Leeds: The University of Leeds, School of Geography (Working Paper 01/01).

Lutz, W. and Qiang, R. (2002). Determinants of human population growth. Philosophical Transactions of the Royal Society B 357(1425): 1197-1210. doi:10.1098/rstb.2002.1121.

McLaughlin, D.K., Lichter, D.T., and Johnston, G.M. (1993). Some women marry young: Transitions to first marriage in metropolitan and nonmetropolitan areas. Journal of Marriage and the Family 55(4): 827-838. doi:10.2307/352765.

Michielin, F. (2004). Lowest low fertility in an urban context: The role of migration in Turin, Italy. Population, Space and Place 10(4): 331-347. doi:10.1002/psp.337.

Milewski, N. (2007). First child of immigrant workers and their descendants in West Germany: Interrelation of events, disruption, or adaptation? Demographic Research 17(29): 859-896. doi:10.4054/DemRes.2007.17.29.

Mulder, C. and Wagner, M. (2001). The connection between family formation and firsttime home ownership in the context of West Germany and the Netherlands. European Journal of Population 17(2): 137-164. doi:10.1023/A:1010706308868.

Sharlin, A. (1986). Urban-rural differences in fertility in Europe during the demographic transition. In: Coale, A. and Watkins, S. (eds.). The Decline of Fertility in Europe. Princeton: Princeton University Press: 234-260.

Snyder, A.R. (2006). The role of contemporary family behaviors in nonmarital conception outcomes of nonmetro women: Comments on Albrecht and Albrecht (2004). Rural Sociology 71(1): 155-163. doi:10.1526/003601106777789774. 
Snyder, A.R., Brown, S.L., and Condo, E.P. (2004). Residential differences in family formation: The significance of cohabitation. Rural Sociology 69(2): 235-260. doi:10.1526/003601104323087598.

Szreter, S. (1996). Fertility, Class and Gender in Britain 1860-1940. Cambridge: Cambridge University Press.

Szreter, S. and Garrett, E. (2000). Reproduction, compositional demography, and economic growth: Family planning in England long before the fertility decline. Population and Development Review 26(1): 45-80. doi:10.1111/j.17284457.2000.00045.x.

Thornton, A. and Philipov, D. (2009). Sweeping changes in marriage, cohabitation and childbearing in Central and Eastern Europe: New insights from the developmental idealism framework. European Journal of Population 25(2): 123-156. doi:10.1007/s10680-009-9181-2.

Watkins, S. (1990). From local to national communities: The transformation of demographic regimes in Western Europe, 1870-1960. Population and Development Review 16(2): 241-272. doi:10.2307/1971590.

Weller, R.H. and Bouvier, L.F. (1972). The three R's: Residence, religion, and reproduction. Demography 9(2): 231-240. doi:10.2307/2060635.

Wilson, C. (2001). On the scale of global demographic convergence 1950-2000. Population and Development Review 27(1): 155-171. doi:10.1111/j.17284457.2001.00155.x.

Zimmer, B.G. and Goldscheider, C. (1966). A further look at Catholic fertility. Demography 3(2): 462-469. doi:10.2307/2060171. 
Kulu, Boyle \& Andersson: High suburban fertility 